\title{
Cyclic Linearization and Island Repair in Sluicing
}

\author{
Chunan Qiu \\ School of Foreign Languages, Jiangsu University of Science and Technology \\ 2 Mengxi Road, Zhenjiang 212003, Jiangsu, China \\ Tel: 86-511-8449-5367 E-mail: chunanqiu@yahoo.cn
}

\begin{abstract}
Cyclic Linearization is adopted to account for the island repair of Sluicing in English. The extraction of wh-phrase out of certain islands undergoes non-successive-cyclic movement, which yields conflicting ordering statements. The derivation can be rescued by deleting all ordering statements in IP, including those conflicting ones. Two arguments concerning Complex NP Constraint (relative clause) and Adjunct Island support the proposal.
\end{abstract}

Keywords: Sluicing, Island Repair, Cyclic Linearization

\section{Introduction}

Since Ross (1969) first raised the issue of Sluicing early in the pre-GB era, it has attracted much attention, thanks to the fact that Sluicing involves the investigation of the structure and the nature of the interfaces, which connects the sound and the meaning components in the computational system. One of the fascinations of Sluicing is that it can violate a wide range of island constraints. In this paper I will explore the island repair under Sluicing and put forward a tentative proposal to account for this puzzle.

\section{Sluicing}

Sluicing is the ellipsis construction illustrated in (1), in which an interrogative clause is elided, leaving only its wh-phrase overt (Note 1).

(1) a. Somebody just left ---Guess [who]. (Ross 1969: 252)

b. She's reading. I can't imagine [what]

Chung et al. (1995) classify Sluicing into two types: Merger cases, as in (1a) in which the wh-remnant has an overt correlate in the antecedent sentence; and Sprouting ones as in (1b) in which no overt correlate is found.

There are two general schools of the analysis of Sluicing: Non-structural approaches and Structural approaches. The former analysis proposes that there is no internal structure in the ellipsis site at any level. Culicover \& Jackendoff (2005) argue that the Sluicing fragment is a very simple clause containing only a DP. The latter school, pursued by the majority of analyses, falls into two approaches in the literature, differing in their assumptions on the role of syntax in the ellipsis. One is the PF Deletion Approach (Ross 1969, Merchant 2001). Merchant (2001) assumes that ellipsis has abstract features of phonetic and phonological representation, but that grammar contains a means of blocking its pronunciation. In Merchant's theory, Sluicing is derived by PF ellipsis of a fully articulated IP (Note 2) out of which a wh-phrase undergoes movement. The Sluice in (2) can be illustrated with Figure 1.

(2) Andy can play something, but I don't know [what [IP Andy can play t]].

The other is LF Copying Approach (Lobeck 1995, Chung et al. 1995). This account maintains that there is a full internal structure in the ellipsis site, but only at the level of LF.

Following the syntactic proposal by Merchant (2001) to account for the derivation of Sluicing, I will discuss the island repair in Sluicing.

\section{Comprehensive Cases of Island Repair}

Ross (1969) noticed that the wh-movement found in Sluicing apparently violates well-known conditions on movement. He observed that island violations as in (a) examples below are significantly improved when Sluicing takes place as in (b) examples.

(3) Complex NP Constraint (noun complement)

a. *I believe the claim that he bit someone, but they don't know [who ${ }_{\mathrm{i}}\left[{ }_{\mathrm{IP}} \mathrm{I}\right.$ believe the claim that he bit $\left.\left.\mathrm{t}_{\mathrm{i}}\right]\right]$.

b. I believe the claim that he bit someone, but they don't know [who].

(4) Complex NP Constraint (relative clause)

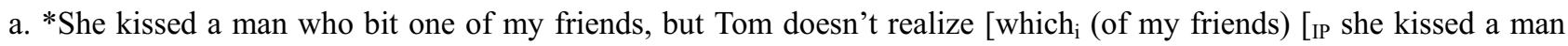


who bit $\left.\mathrm{t}_{\mathrm{i}}\right]$ ].

b. She kissed a man who bit one of my friends, but Tom doesn't realize [which (of my friends)].

(5) Coordinate Structure Constraint

a. *Irv and someone were dancing together, but I don't know [who $\mathrm{w}_{\mathrm{i}}$ Irv and $\mathrm{t}_{\mathrm{i}}$ were dancing together]].

b. Irv and someone were dancing together, but I don't know [who].

(6) Sentential Subject Constraint

a. *That he'll hire someone is possible, but I won't divulge [who ${ }_{\mathrm{i}}$ [IP that he'll hire $\mathrm{t}_{\mathrm{i}}$ is possible]].

b. That he'll hire someone is possible, but I won't divulge [who].

Besides these examples, it seems that Sluicing can overcome a much wider range of syntactic islands. More examples are given below. (data from Merchant 2001)

(7) Adjuncts

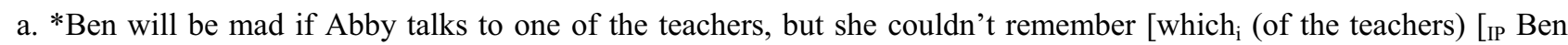
will be mad if Abby talks to $\left.t_{i}\right]$ ].

b. Ben will be mad if Abby talks to one of the teachers, but she couldn't remember [which].

(8) Subject Island

a. *A biographer of one of the Marx brothers interviewed her, but I don't remember [which (Marx brother) [IP a biographer of one of $t_{i}$ interviewed her]].

b. A biographer of one of the Marx brothers interviewed her, but I don't remember [which].

If the (b) examples in (3-8) are derived from the (a) examples through wh-movement and PF deletion, the question arises as to why there are no island effects. Ross (1969) concluded that the Sluicing deletion could repair island violations, with syntactic violations calculated globally across the derivation.

\section{Previous Accounts and Their Problems}

Many researchers have discussed the island repair phenomenon under ellipsis. In this section I will examine some influential accounts and point out their problems.

\subsection{Chomsky (1972)}

Chomsky (1972) suggests that Sluicing does indeed involve long wh-movement, and that island violations can be repaired. He assumes that when an island is crossed by a movement operation the island node can be marked with an output condition forbidding $*$ in surface structures. He presents an example involving extraction out of a noun complement.

(9) a. *He has plans to send some of his children to college, but I don't know [which one [IP $_{\mathrm{i}}$ he has plans to send $t_{\mathrm{i}}$ to college]].

b. He has plans to send some of his children to college, but I don't know [which one].

Chomsky's analysis is illustrated in Figure 2.

Wh-movement extracts the DP which children from its base position (marked by $t$ ) to the highest [Spec, CP]. The complex NP island (noun complement) is crossed, so it is marked with a *. In non-elliptical example as in (9a), when this *DP reaches PF, it will cause a PF-crash, since * is by hypothesis PF uninterpretable. The operation of Sluicing will prevent the * from triggering a PF-crash, by deleting IP containing the *DP.

\subsection{Merchant $(2001,2008)$}

Attractive as Chomsky (1972) is, the account faces a serious problem in that it falsely predicts that any type of ellipsis that deletes an island node should repair the violation. But the fact is that VPE (VP-ellipsis) can not do the same job. The extraction out of a VPE site is as ungrammatical as its non-elliptical case, as in (10).

(10) Relative Clause Island

a. *She kissed a man who bit one of my friends, but Tom doesn't realize which (of my friends) she [vp kissed a man who bit $\mathrm{t}_{\mathrm{i}}$. (no ellipsis)

b. * She kissed a man who bit one of my friends, but Tom doesn’t realize which (of my friends) she did. (VPE)

Sluicing repair this very island violation in (4b). Therefore, Merchant (2001) rejects Chomsky's account, and argues that the island insensitivity of wh-movement requires two different kinds of solutions, depending on the kind of island involved. Some are the result of a variety of PF violations, which include Left Branch Extractions, That Trace Effects, 
Subject Island, and Coordinate Structure Constraint, and others are due to LF violations, which contain relative clauses, sentential complements to head nouns and adjuncts. Only the former can be repaired by PF deletion. By contrast, the latter involves extraction out of propositional domains, and it is not repairable by deletion. That is why (10b) remains bad. He claims that propositional islands involve no island at all, but short extraction. The Sluice in (4b) has the following structure:

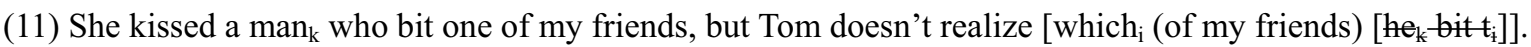

A major assumption by Merchant (2008) is to think of* as a feature of traces, instead of thinking of it as a feature of island nodes as in Chomsky (1972). He suggests that when an island is crossed, the newly created intermediate trace or copy will be marked with the * feature, and all later copies of this * item will also be given *-marking. A standard island effect will then arise whenever intermediate *-traces survive until PF. Sluicing in (12a) is illustrated with the derivation in $(12 b)$.

(12) a. They want to hire someone who speaks a Balkan language, but I don't remember [which (Balkan language)].

b. *They want to hire someone who speaks a Balkan language, but I don't remember [CP which (Balkan language)[IP *t"'[IP they [VP *t"[want to hire someone [CP *t'[CP who speaks t]]]]]]].

The grammaticality of (12a) is due to the deletion of the highest IP, with all the *-marked traces eliminated from the PF-representation. In doing so, the island effects are missing. (Note 3)

\subsection{Problems of Previous Accounts}

The island repair puzzle has inspired some influential analyses, but these accounts are not unproblematic. As mentioned above, Chomsky' (1972) account faces a serious setback, in that the elliptical sentence can still be ungrammatical even though the island node is deleted in VPE, as in (13b) and many other VPE cases in various island environments. (see Merchant 2008)

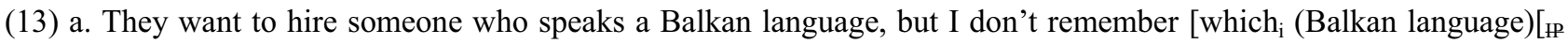
they want to hire someone $*$ [who speaks $\left.\mathrm{t}_{\mathrm{i}}\right]$ ]]. (Sluicing)

b. * They want to hire someone who speaks a Balkan language, but I don't remember [which $\left(\right.$ Balkan language) $^{2}$ they do [wp-want to hire someone *[who speaks $\left.\left.\left.\mathrm{t}_{\mathrm{i}}\right]\right]\right]$. (VPE)

The Sluicing in (13a) is grammatical since the *-marked relative clause island node is deleted, as Chomsky (1972) predicts. The VPE in (13b), however, is ungrammatical even though the *-marked island node is eliminated, contrary to his prediction.

Merchant (2001) argues that what he calls Propositional Islands (including relative clauses as in (13)) are LF islands, rather than PF islands; thus this kind of island cannot be repaired by a PF deletion. Therefore, he proposes that the derivation as in (13) doesn't contain an island violation. However, in his influential book The Syntax of Silence, we find that he bases his arguments for form-identity effects (Note 4) on comprehensive data in islands context, especially relative clauses (Merchant 2001: 90, 104). If these examples indeed contain no islands, then Sluicing will never repair island violation, contrary to the fact. Therefore, his proposal is disturbing and it weakens the form-identity effects.

Instead of thinking of * as a feature of island nodes as in Chomsky (1972), Merchant (2008) consider * as feature of traces. However, as Kitahara (1999) argues, the assumption that a *-feature enters into a derivation as the output of certain environments contradicts the Inclusiveness Condition (Chomsky 1995), since it is not a lexical feature and appears nowhere in the lexicon.

\section{A New Approach to Island Repair in Sluicing}

Following the commonly accepted assumption that PF ellipsis can repair islands in Sluicing, I will adopt a more recent approach to explain the examples involving island repair.

\subsection{Cyclic Linearization (Fox \& Pesetsky 2005)}

Fox and Pesetsky ( 2005) propose Cyclic Linearization to account for the mapping between syntax and phonology, by suggesting that phonology determines the linear ordering of words. The core of their proposal is Linearization Preservation:

The linear ordering of syntactic units is affected by Merge and Move within a Spell-out Domain, but is fixed once and for all at the end of each Spell-out Domain.

Fox and Pesetsky (2005) argue that the list of Spell-out Domains includes at least CP, DP, and vP/VP. (Note 5) Ordering statements are collected at the end of each Spell-Out domain and are added to the ordering table. As a result of Linearization Preservation, the ordering table must not contain contradictory statements. They suppose a bottom-to-top derivation has created the syntactic domain D in (14), where D is also a Spell-out domain. The Spell-out operation establishes the ordering statements given below. 
(14) $[\mathrm{D} X \mathrm{Y} Z]$

Ordering:

$\mathrm{X}<\mathrm{Y}$

$\mathrm{Y}<\mathrm{Z}$

The expression " $\mathrm{X}<\mathrm{Y}$ " should be read as " $\mathrm{X}$ precedes $\mathrm{Y}$ ". This is an ordering statement understood by PF, which means that the last element of X precedes the first (non-trace) element of Y. Suppose that after Spell-out applies to D, the syntax merges $\alpha$ with $\mathrm{D}$, yielding (15).

(15) $\alpha[\mathrm{D}$ X Y Z]

Consider a situation in which some element in D undergoes leftward movement into the higher Spell-out domain. Let's examine two possible scenarios, depending on whether or not the element that moves out of D previously occupies its left edge.

(16) Scenario 1 (leftward movement from a left-edge position)

Insert Figure 3 Here

Ordering in D:

$\mathrm{X}<\mathrm{Y}$

$\mathrm{Y}<\mathrm{Z}$

Ordering in D':
a. $\mathbf{X}<\alpha$
b. $\alpha<D$
c. $\alpha<\mathrm{Y}$
d. $\mathbf{X}<\mathbf{Y}$

When the next domain D' (containing $\alpha$ and D) is spelled out, the linearization of D' will add the new (boldfaced) ordering statements listed in (16). Note that $\alpha<\mathrm{Y}$ is a consequence of Linearization Preservation. The expression " $\mathrm{X}<$ $\mathrm{Y}$ " in D' is a result of transitivity of the precedence relation ' $<$ '. Because $\mathrm{X}$ was at the left edge of $\mathrm{D}$, the ordering statements added in D' are consistent with those previously added in D. Therefore, leftward movement from the left edge of a Spell-out Domain obeys Linearization Preservation and yields no ordering contradictions.

Suppose instead that $Y$ in (17) overtly moves to the left of $\alpha$. When D' is spelled out, it will include all the ordering statements from $\mathrm{D}$ as well as the new ordering statements as in (17).

(17) Scenario 2 (leftward movement from a non-left-edge position)

Insert Figure 4 Here

Ordering in D:

$\mathrm{X}<\mathrm{Y}$

$\mathrm{Y}<\mathrm{Z}$

Ordering in D':

a. $\mathbf{Y}<\alpha$

b. $\alpha<\mathrm{D}$

c. $\alpha<\mathrm{X}$

d. $\mathbf{Y}<\mathbf{X}$

Consider the new ordering statements in D': Y precedes $\alpha$, and $\alpha$ precedes D. Linearization requires that $\alpha$ must precede X. Consequently, Y precedes X; conflicting statements arise, as shown in boxed ordering statements in (17).

It is safe to conclude that a wh-phrase undergoes successive-cyclic movement, thus it cannot cross the edge of a Spell-out Domain. Furthermore, leftward movement from a Spell-out Domain D must take place from the left edge of D. Finally, non-successive-cyclic movement is generally possible, when linearization is not necessary. Therefore, leftward movement from a non-left-edge position is supposed to be non-successive-cyclic, resulting in a PF-crash.

\subsection{Cyclic Linearization and Sluicing}

Reconsider the situation in (17), repeated here as in (18). $\mathrm{Y}$ is attracted to the left of $\alpha$, but a property of D prevents $\mathrm{Y}$ from first moving to the left edge of D, so $\mathrm{Y}$ undergoes non-successive-cyclic movement to its final landing site. Then 
the problem arises because contradicting statements appear at the ordering table.

On the assumption that island is such a property of D that leads to non-successive-cyclic movement, I suppose D in (18) is subject to ellipsis under the condition proposed by Merchant (2004); then any ordering statement that makes reference to $\mathrm{X}$ (or $\mathrm{Z}$ ) has no impact on pronunciation; therefore, the overt movement of $\mathrm{Y}$ does not bring about conflicting statements. The deleted ordering statements are shown with strikethrough as below.

(18) Insert Figure 5 Here

Ordering in D:

\section{$\mathrm{X}<\mathrm{Y}$}

$\mathrm{Y}<\mathrm{Z}$

Ordering in D':

a. $\mathbf{Y}<\alpha$

b. $a<\boldsymbol{B}$

c. $\alpha<X$

d. $\mathbf{Y < X}$

Consider the cases in Sluicing. I assume that the extraction of wh-phrase out of certain islands undergoes non-successive-cyclic movement to the highest [Spec, CP]. This kind of movement will result in conflicting ordering statements in ordering table. I further propose that the contradiction of statements will be removed by deleting all ordering statements in IP; then the derivation is rescued.

\subsection{Explaining Data}

I'll give two examples concerning Complex NP Constraint (relative clause) and Adjunct Island to illustrate my proposal. First consider relative clause as in (19):

(19) *They want to hire someone who speaks a Balkan language, but I don't remember [CP2 which (Balkan language) [IP they $\mathrm{VP} 2$ _ want to hire someone [CP1 who VP1 _ speaks _ ] ]

The wh-phrase which (Balkan language) functions as the complement of the verb speaks. It first moves to [Spec, VP1]. The linearization of VP1 yields the following:

\section{(20) Spell-out applies to VP1:}

which $<$ speaks

Because [Spec, CP1] is occupied by who, the wh-phrase which has to move from [Spec,VP1] directly to [Spec, VP2], without stopping in the specifier of $\mathrm{CP} 1$. The linearization of CP1 will be as follows:

\section{(21) Spell-out applies to CP1:}

who $<$ which $<$ speaks

And Spell-out of VP2 yields the following ordering information:

\section{(22) Spell-out applies to VP2:}

which $<$ VP2 $<$ CP1

The wh-phrase which finally moves to [Spec, CP2]. Spell-out of CP2 has the following ordering information:

\section{(23) Spell-out applies to CP2:}

which $<$ they $<$ VP2

The information in (21) and (23) impose conflicting requirements on the phonology. In (21) which must be pronounced after who, but (23) requires which to be pronounced before who (it is contained in VP2). The derivation violates Linearization Preservation, because contradictory ordering statements appear at the ordering table. The reason for this is that which has crossed Relative Clause Island, which renders a left-edge landing site for wh-movement unavailable. That's why (19) is ungrammatical.

In accordance with my proposal, the contradictory ordering statements can be eliminated by PF deletion of IP. Through IP ellipsis the grammatical sentence, namely Sluicing, is derived as illustrated in (24).

(24) a. They want to hire someone who speaks a Balkan language, but I don't remember [CP2 which (Balkan language)[ip

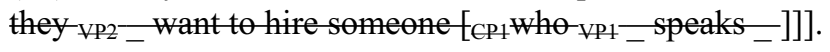

b. They want to hire someone who speaks a Balkan language, but I don't remember [which (Balkan language)].

Next let's consider the example Adjunct Island is involved, as in (25): 
(25) *Ben will be mad if Abby talks to one of the teachers, but she couldn't remember [CP2which (of the teachers) [IP Ben will be mad [CP1 if Abby [vp1_ talks to _ ] ]]].

The wh-phrase which (of the teachers) first moves to [Spec, VP1]. Apply Spell-out to VP1:

\section{(26) Spell-out applies to VP1:}

which $<$ talks to

CP1 is a Spell-out Domain that lacks a left-edge landing site for movement. Thus, the wh-phrase which has to move directly to [Spec, CP2], crossing the adjunct island. Since CP1 is a Spell-out Domain, the linearization of the relevant elements in $\mathrm{CP} 1$ yields the following ordering information.

\section{(27) Spell-out applies to CP1:}

if Abby < which < talks to

Apply Spell-out to CP2:

\section{(28) Spell-out applies to CP2:}

which $<$ Ben will be $\operatorname{mad}<\mathrm{CP} 1$

The ordering information in (27) contradicts that in (28). In (27), which go after if Abby, but in (28) which precedes if Abby. The conflicting ordering statements will bring about difficulty in pronunciation. But if the relevant items are deleted, there will be no contradictions. All the ordering statements will be eliminated with IP ellipsis; then the derivation is rescued, as in (29).

(29) a. Ben will be mad if Abby talks to one of the teachers, but she couldn't remember [ ${ }_{\mathrm{CP} 2}$ which (of the teachers) [IP Ben will be mad [CP1 if Abby [vp1_talks to_ $]$ ] ]].

b. Ben will be mad if Abby talks to one of the teachers, but she couldn't remember [which (of the teachers)].

\section{Conclusion}

The paper explores the nature of Sluicing, that is, island constraints seem to be violated with grammatical examples. But if the Sluicing sentences are derived from their non-elliptical sources through wh-movement and PF-deletion, the puzzle arises as to why there are no island effects. On the assumption that the extraction of wh-phrase out of certain islands undergoes non-successive-cyclic movement, which yields conflicting ordering statements, I argue that the derivation can be rescued by deleting all ordering statements in IP, including those conflicting ones. I have tentatively put forward a new proposal to solve the island repair puzzle. However, there are some residual problems that need further study. My approach cannot account for the differences between IP ellipsis (Sluicing) and VP ellipsis. VPE seems to be impossible in certain contexts where Sluicing allows for island repair. In addition, the paper does not deal with Sprouting Sluicing, which does not exhibit the same island repair effect.

\section{References}

Chomsky, N. (1972). Some Empirical Issues in the Theory of Transformational Grammar. In S. Peters(Ed.), The Goals of Linguistic Theory. Englewood Cliffs: Prentice-Hall Inc., pp. 63-130.

Chomsky, N. (1995). The Minimalist Program. Cambridge, Mass.: MIT Press.

Chomsky, N. (2001). Derivation by Phase. In M. Kenstowicz (Ed.), Ken Hale: A Life in Language. Cambridge, Mass.: MIT Press, pp. 1-52.

Chung, S., W. Ladusaw, \& J. McCloskey. (1995). Sluicing and logical form. Natural Language Semantics, 3, 239-282.

Culicover, P. and R. Jackendoff. (2005). Syntax Made Simple(r). Oxford: Oxford University Press.

Fox, D. \& D. Pesetsky. (2005). Cyclic linearization of syntactic structure. Theoretical Linguistics, 31, 1-45.

Kitahara, H. (1999). Eliminating * as a feature (of traces). In Samuel D. Epstein and Norbert Hornstein (Eds.), Working minimalism. Cambridge, Mass.: MIT Press, pp. 77-93.

Lobeck, A. (1995). Ellipsis: Functional Heads, Licensing, and Identification. New York: Oxford University Press.

Merchant, J. (2001). The Syntax of Silence: Sluicing, Islands, and Identity in Ellipsis. Oxford/New York: Oxford University Press.

Merchant, J. (2004). Fragments and ellipsis. Linguistics and Philosophy, 27, 661-738.

Merchant, J. (2008). Variable island repair under ellipsis. In K. Johnson (Ed.), Topics in Ellipsis. Oxford: Oxford University Press, pp. 132-153.

Ross, J. R. (1969). Guess who?. In R. Binnick et al.(Eds.), Papers from the Fifth Regional Meeting of the Chicago Linguistics Society. Chicago: Chicago Linguistic Society, pp. 252-286. 


\section{Notes}

Note 1. The Sluicing sentences are bracketed throughout the paper.

Note 2 . The phonetically deleted constituent is indicated with strikethrough in this paper.

Note 3. The final copy of which (Balkan language), located in the highest [Spec, CP] in (12b) is not marked with *, since the *-feature of the final copy is checked by E-feature, which is located on C. (Merchant 2004)

Note 4. The form-identity effect is the crucial evidence for Merchant's (2001) 'Movement + Deletion' account of Sluicing, The wh-remnant crosslinguistically shows similar behavior across a wide range of grammatical dependencies to its wh-phrase counterpart in regular, non-elided questions. These cases include case marking and preposition stranding.

Note 5. Fox \& Pesetsky (2005) combine their proposal with the Phase Theory (Chomsky 2001). Therefore, Spell-out Domains roughly correspond to Chomsky's notion of phase. In this sense I develop my proposal under the Phase Theory, by using the term 'Spell-out Domain'.

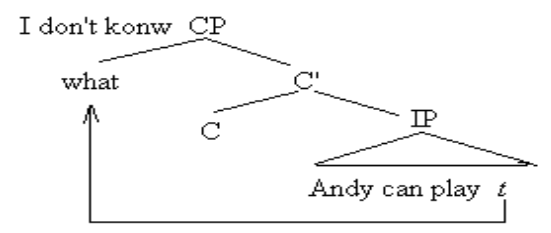

Figure 1. Andy can play something, but I don’t know

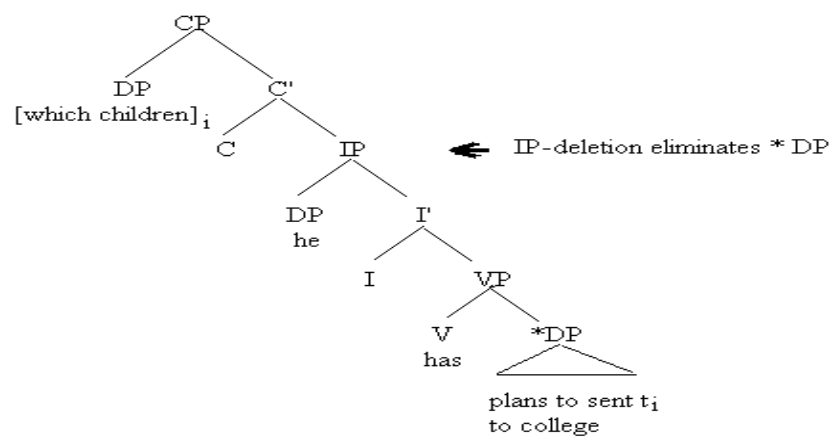

Figure 2. He has plans to send some of his children to college, but I don't know

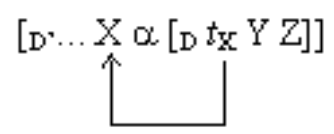

Figure 3. leftward movement from a left-edge position

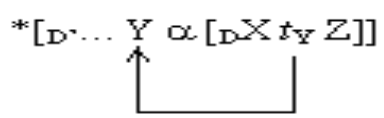

Figure 4. leftward movement from a non-left-edge position

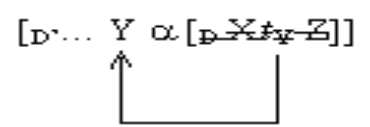

Figure 5. leftward movement from a non-left-edge position (ellipsis) 